\title{
EL FRAUDE EN LA HIDALGUÍA: INTRUSIONES EN EL ESTADO DE HIJOSDALGO DURANTE EL SIGLO XVIII ${ }^{1}$
}

\author{
Jorge PÉREZ LEÓN \\ Universidad de Valladolid
}

RESUMEN: Durante la Edad Moderna y especialmente durante el siglo XVIII, la hidalguía, como condición privilegiada, fue ambicionada por gran parte de la población. Aunque su acceso estaba cerrado a la mayor parte de la población pronto se diseñaron procedimientos para burlar este obstáculo como el fraude y la manipulación de las pruebas de nobleza. En el espacio local esta problemática se centra en las intrusiones en el estado noble, una cuestión que no solo se limitará al enfrentamiento entre plebeyos e hidalgos sino que también afectará a los intereses del Estado.

PALABRAS CLAVE: intrusos, nobleza, Chancillería, hidalguía, prueba documental, padrones.

ABSTRACT: During Modernity and especially during the 18th century, the "hidalguía", as a privileged condition, was sought by a great number of people. Though his access was closed to most of them, soon some procedures were designed to bypass this obstacle, such as fraud and the manipulation of the "hidalguía" proofs. At the local sphere this problematic focuses on the intrusions on the noble condition, a question that will not only limit itself to the clash between the common people and the "hidalgos" but will also damage the interests of the State.

KEYWORDS: Intruders, nobility, Chancillería, hidalguía, documentary evidence, polls.

\section{EL FRAUDE EN LA HIDALGUÍA: INTRUSIONES EN EL ESTADO DE HIJOSDALGO DURANTE EL SIGLO XVIII ${ }^{2}$}

La manipulación de pruebas en genealogías y probanzas de hidalguía durante la Edad Moderna ha sido objeto de estudio en diversas ocasiones aunque, sin embargo, este tipo de investigaciones apenas han profundizado en las

\footnotetext{
${ }^{1}$ Recibido el 2 de septiembre y aceptado para su publicación el 3 de noviembre de 2010.

2 Esta investigación se realiza con el apoyo de una Beca FPI de la Junta de Castilla y León.
} 
repercusiones que estos procedimientos ilícitos tenían sobre los sectores ajenos a las élites de las grandes ciudades ${ }^{3}$.

Es notorio que el orden estamental no era, en absoluto, un sistema rígido sino que los movimientos de ascenso y descenso social eran habituales, especialmente en la oscura frontera que separaba nobleza y villanía. Para analizar esta movilidad social, primordialmente la de carácter ilícito, nos centraremos en dos aspectos. En primer lugar, en los procedimientos utilizados en la falsificación y manipulación de la documentación acreditativa de nobleza, fundamentalmente en los padrones de distinción de estados e informaciones de filiación y nobleza. Los primeros, funcionaban como registro socio-fiscales de la adscripción estamental de los vecinos de localidad; las segundas, calificaban y acreditaban el estado que correspondía al solicitante. En segundo lugar, analizaremos las repercusiones que dichas prácticas tenían tanto en el orden social de los pequeños y mediados municipios como sobre la legislación real en materia de hidalguía.

Para este acercamiento hemos trabajado a partir de dos perspectivas: por un lado, el ámbito local, origen y destino de las prácticas fraudulentas; por otro, la postura de la Corona frente a este tipo de irregularidades a través de las Salas de Hijosdalgo de las Reales Chancillerías de Valladolid y Granada, encargadas de los asuntos de hidalguía. Ante la escasez de estudios concretos sobre el tema el análisis de las fuentes jurídicas y judiciales -básicamente legislación y procesos judiciales sobre fraudes procedentes de los fondos del Archivo de la Chancillería de Valladolid- se convierte en una herramienta de estudio primordial para su investigación. No obstante, ante las limitaciones que impone la casuística, nuestros objetivos se limitan a identificar algunas de las pautas básicas que siguen tales prácticas que, en muchas ocasiones, lejos de ser simples hechos aislados ilustran a la perfección la sociedad y la mentalidad de su época.

${ }^{3}$ En esta línea de investigación destacan los estudios sobre la manipulación genealógica en relación con la cuestión conversa. Vid J. CONTRERAS CONTRERAS (1995). «Linajes y cambio social: la manipulación de la memoria». Historia Social, 21, pp. 105-124; E. SORIA MESA (1997). El cambio inmóvil. Transformaciones y permanencias de una élite de poder (Córdoba, ss. XVI-XIX). Córdoba: Ediciones La Posada; E. SorIA MESA (2004). «Genealogía y poder. Invención del pasado y ascenso social en la España moderna». Estudis. Revista de Historia Moderna, 30, pp. 21-55. Por último, merece la pena mencionar el trabajo de Calleja Puerta sobre un caso concreto de falsificación en los albores de la Modernidad: M. CALleja PuERTA (2004). «Historia y falsificación en las pruebas de hidalguía de un caballero andaluz: un estudio histórico-diplomático». En Sulcum Sevit: estudios en homenaje a Eloy Benito Ruano. Oviedo: Universidad, Facultad de Geografía e Historia, I, pp. 397416. 


\section{EL FRAUDE Y EL ACCESO A LA NOBLEZA}

La sociedad española del Antiguo Régimen y, especialmente la del siglo XVIII, se caracterizó por una apetencia desmedida por los signos de distinción propios de la nobleza. En el caso de las capas altas su máxima aspiración era lograr un título nobiliario o, en su defecto, un hábito de Orden Militar. Mientras tanto las capas intermedias y bajas de la población ansiaban acceder también a un nivel superior de distinción pero centrando su atención en la hidalguía. Para acceder a esta categoría nobiliaria disponían de dos opciones: una, por la vía legal, mediante matrimonios desiguales, compra o servicios a la Corona; otra, de forma ilícita, mediante la manipulación de documentos y probanzas.

La nobleza, como grupo privilegiado, va a imponer una serie de reservas bajo la forma de impedimentos legales como el linaje -de sangre noble-, la limpieza de sangre o los prejuicios respecto a los oficios mecánicos, tenidos como viles y deshonrosos, estableciendo así todo un repertorio de reservas - de inclusión o de exclusión- que conforman el principio de cierre del estamento ${ }^{4}$. Por ello, en una sociedad donde la máxima aspiración es la nobleza, la ruptura de las barreras estamentales se convierte en una reacción consustancial al mismo sistema ${ }^{5}$.

Es aquí donde la calidad del linaje, como una expresión más de la identidad personal, tiene una repercusión directa sobre la propia consideración social del individuo. Este criterio va a regir buena parte del entramado de relaciones entre los sectores más poderosos pero también entre las capas inferiores ya que la reproducción de modelos de comportamiento y valores propios de la aristocracia es una constante en el conjunto de esta sociedad de corte castizo-estamental ${ }^{6}$. De ahí que la importancia social otorgada al linaje no era un comportamiento privativo de las clases más elevadas, capaces de acceder a un matrimonio ventajoso, acceder a cargos públicos u obtener un hábito de orden militar o un título nobiliario sino que tenía su reflejo en todos los estratos de la población.

\footnotetext{
${ }^{4}$ J.A. Maravall (1989). Poder, honor y élites en el siglo XVII. Madrid: Siglo XXI de España Editores, p. 80 .

5 Alberto Marcos ha profundizado en la cuestión de la movilidad social dentro del estamento nobiliario, tanto de ascenso al mismo como de desclasamiento, procesos paralelos que contribuyen a reforzar el propio Sistema. Vid A. MARCOS MARTín (2007). «Movilidad social ascendente y movilidad social descendente en la Castilla moderna». En GómEZ GONZÁLEZ, I. y LóPEZ-GUADALUPE MuÑoz, M. L. (eds). La movilidad social en la España del Antiguo Régimen. Granada: Comares Historia, pp. 19-48.

${ }^{6}$ Sociedad en la que la propia nobleza emplea la exigencia de la limpieza de sangre como instrumento de preservación de su identidad socioeconómica. Vid J. I. GUTIÉRREZ NIETO (1973). «Estructura castizo-estamental de la sociedad castellana del siglo XVI». Hispania, 125, pp. 538-540.
} 
Por ello, en función del criterio dual de estratificación (nobleza-limpieza), una lustrosa ascendencia sería una condición imprescindible de acuerdo con los criterios impuestos por la élite política y social como principio de cierre del estamento. En respuesta a estos criterios excluyentes conversos y plebeyos elaboraron sus propias estrategias para eludirlos, generalmente mediante prácticas ilícitas como la falsedad documental y testifical. De hecho, durante el siglo XVII el fraude genealógico llegó a tal extremo que afectó a todo el estamento nobiliario ocultando toda imperfección y mancha en su pasado ${ }^{7}$. En palabras de Jaime Contreras esta manipulación de la memoria, junto a otras prácticas como los matrimonios desiguales, promovió la movilidad social de los grupos equiparando su consideración social con su poder económico ${ }^{8}$. En este sentido la riqueza se erigió en un factor determinante para el desarrollo de tales estratagemas. El mejor ejemplo de su importancia lo hallamos en los servicios de los hambrientos genealogistas, auténticos expertos en la fabricación de las más pintorescas ascendencias a cambio de un salario? .

En el ámbito local la exclusión social se manifestó a través de un criterio netamente estamental: la distinción entre privilegiados y no privilegiados, es decir, el hidalgo frente al pechero. La hidalguía, escalón inferior de la nobleza castellana a la par que fundamento de toda nobleza de sangre, quedaba definida dentro del ámbito local en base a sus privilegios de sangre y por su oposición al pechero o plebeyo, el no privilegiado.

En muchas localidades esta oposición jurídica entre ambos colectivos se consolidaba con la distinción de estados que se expresaba a su vez a través de la mitad de oficios concejiles y los padrones de distinción de estados. Otra expresión del privilegio era la exención fiscal de los nobles en contribuciones como la moneda forera ${ }^{10}$ o el servicio ordinario y extraordinario ${ }^{11}$ cuyo pago recaía exclusivamente en los pecheros y que era origen de continuas disputas entre ambos estados. Para registrar el cobro de estos impuestos se alistaba a la población en orden a su calidad en los mencionados padrones de distinción de estados. Este no

${ }^{7}$ A. Dominguez OrTiz (1985). Las clases privilegiadas en el Antiguo Régimen. Madrid: Istmo, pp. 20-22.

${ }^{8}$ J. CONTRERAs CONTRERAs (1995). art. cit., pp. 115-117; E. SORIA MESA (2007). «Ascenso social y legitimación en la Granada Moderna: la Real Maestranza de Caballería». En GómEz GonzÁLEz, I. y LóPez-Guadalupe Muñoz, M. L. (eds.). La movilidad social en la España del Antiguo Régimen. Granada: Comares, pp. 173-192.

${ }^{9}$ E. SORIA MESA (2004). art. cit., pp. 23-28.

${ }^{10}$ Abolido en 1724. Novísima Recopilación. Lib. VI, Tít. XVII, 1. X

${ }^{11}$ Abolido en 1795. Ibídem. Lib. VI, Tít. XVII, 1. XII 
solo era un instrumento con fines fiscales sino que también representaba uno de los actos positivos de nobleza más importantes, prueba de la posición que correspondía a una familia, de modo que el cuestionamiento de la adscripción de un vecino suponía una afrenta directa a su honor y a la notoriedad de su calidad. Estos agravios debían resolverse ante la Sala de Hijosdalgo de la Chancillería de Valladolid o de Granada, únicas instancias judiciales con la capacidad para reconocer la hidalguía de forma vinculante.

Hasta la implementación del auto acordado de 1703 -del que trataremos más adelante- el reconocimiento de la hidalguía estuvo estrechamente ligado al carácter voluble de los concejos. La tolerancia de los empadronadores del estado noble a la hora de admitir como hidalgos a los recién avecindados chocaba frontalmente con la actitud del estado llano -siempre interesado en repartir los pechos entre el mayor número de vecinos- tendente a empadronar como pecheros a todos aquellos sobre los que había reservas sobre su calidad ${ }^{12}$.

La informalidad legal de estos avecindamientos hacía que, en función de la actitud del concejo, se produjesen dos reacciones contrapuestas: si el individuo que pretendía ser reconocido como hidalgo contaba con la aprobación o, simplemente, con la permisividad del concejo su pretensión no encontraría muchos obstáculos dada la notoria calidad del presunto hidalgo entre la comunidad sin necesidad de presentar ningún aval acreditativo que respaldase ese dictamen.

Este es el caso de Alonso de Castañeda quien, recién llegado de la Montaña, se avecindó en la villa manchega de Almagro. Por su presunto origen montañés logró que desde 1575 se le inscribiese como hidalgo en los alistamientos aunque con notas como "vino de la Montaña, dicen que es hidalgo" y "dudoso". A pesar de estas razonables dudas Castañeda nunca vería disputada su calidad ni la de sus descendientes ${ }^{13}$. La misma autonomía en lo relativo a recibimientos y adjudicación de estados puede constatarse en las grandes ciudades. En un concejo tan aristocratizado como Córdoba el respeto a la legislación vigente en cuanto a recibimientos era, cuanto menos, "peculiar" y los padrones eran manejados a

12 G- ANES y ÁlvAREZ DE CASTRILlÓN (2006). «Hijosdalgo y hombres buenos en la España cervantina». Boletín de la Real Academia de la Historia, CCIII, p. 8. También Fayard ha abordado esta cuestión analizando las facilidades que los plebeyos tenían para introducirse en el estado noble, de los medios de que se valían para ello así como la autonomía de los concejos en materia de recibimientos. Vid J. FAYARD (1983). Los miembros del Consejo de Castilla (1621-1746). Madrid: Siglo XXI de España Editores, pp. 185-193.

${ }_{13}$ Archivo de la Real Chancillería de Valladolid [en adelante ARChV], Sala Hijosdalgo-Pleitos, C. 1071-24. Información procedente del expediente provisional de hidalguía solicitado por el tataranieto, Sebastián de Castañeda y Armendáriz (1715). 
conveniencia de los jurados ${ }^{14}$. La elite tradicional logroñesa, de extracción hidalga, intentó monopolizar el poder impidiendo el acceso a la hidalguía de pecheros enriquecidos implantando diversos mecanismos de cierre lo que no impidió su definitiva integración tras un largo proceso de luchas internas ${ }^{15}$.

Por el contrario, allí donde el estado pechero local era reacio a recibir a nuevos vecinos exentos los obligaban sistemáticamente a contribuir en el reparto de servicios y llegado el caso acudían a la Chancillería a denunciar la pechería de los demandados. De este modo los presuntos hidalgos, si sus recursos se lo permitían, no tenían otra alternativa que acudir a la Real Chancillería para entablar pleito de hidalguía contra el concejo y obtener su reconocimiento legal mediante una Real Carta Ejecutoria de hidalguía evitando así caer en la pechería ${ }^{16}$.

Hubo estados llanos especialmente hostiles con sus homónimos nobles como el del concejo segoviano de Pedraza de la Sierra cuya acendrada oposición frente a los hidalgos de la localidad lo llevaban a atacar, no solo a recién llegados, sino también a familias de reconocida nobleza en su jurisdicción ${ }^{17}$.

Como vemos, aunque legalmente la competencia para determinar el estado de hijodalgo recaía exclusivamente en la Sala de Hijosdalgo de la Real Chancillería de Valladolid y de Granada ${ }^{18}$ la realidad era que las autoridades locales se adjudicaban de facto dicha atribución, acudiéndose ante el tribunal regio cuando una de las partes no quedaba satisfecha en su pretensión. Los numerosos procesos que se conservan en el Archivo de la Real Chancillería de Valladolid evidencian que la

${ }^{14}$ E. SORIA MESA. (1997). op. cit., pp. 146-148.

15 P. L. LORENZO CADARSO (1989). «Luchas políticas y refeudalización en Logroño en los siglos XVI Y XVII». Historia Social, 5, pp. 17-22.

${ }^{16}$ Existen varios estudios que ejemplifican la resistencia de los concejos, entre ellos: Vid M.C., Gerbet, J. FAyARD, J. (1985). «Fermeture de la noblesse et pureté de sang dans les concejos de Castille au XVème siécle a travers les procès d'hidalguía». En la España Medieval, 6, pp. 469-473; C. M. CREMADES GriÑÁN, (1985). «El repartimiento del servicio ordinario en el concejo de Barrax: una afrenta para la familia de Arce». Contrastes. Revistas de Historia Moderna, 1, pp. 51-72.

17 J. PÉREZ LEÓN. (2010). «Hidalgos contra el Concejo de Pedraza (Segovia): el pleito de hidalguía de los Suárez de Figueroa, ausentes en Indias». En CARRASCO, A. [ET AL.] (eds). Conflictos y sociedades en la historia de Castilla y León: aportaciones de jóvenes historiadores. Valladolid: Universidad de Valladolid pp. 359-372. Estos son apenas dos ejemplos pero los pleitos de hidalguía motivados por la parcial actitud de los concejos son numerosos durante toda la Edad Moderna tal y como puede observarse en los fondos de los archivos de la Real Chancillería de Valladolid y de Granada.

18 Pragmática de Córdoba de 30 de mayo de 1492. Vid Novísima Recopilación. Lib. XI, Tít. XXVII, 1. IV. 
aspiración a la hidalguía fue una constante durante la Edad Moderna aunque rodeada por intereses muy diversos, tantos como los privilegios a que daba acceso: exención fiscal, promoción social, inmunidad personal en caso de contraer deudas civiles, etc.

Nuestro análisis se centrará en el estudio de los múltiples ardides empleados para adherirse a la nobleza local que van desde la manipulación o la destrucción de las pruebas de la pechería en los padrones hasta la más compleja falsificación de documentos acreditativos de nobleza expedidos por un tribunal real como las Cartas Ejecutorias de hidalguía.

\section{EL INTRUSISMO EN EL ESTADO DE HIJOSDALGO Y SUS MECANIS- MOS DURANTE EL SIGLO XVIII}

El estudio de los núcleos rurales ha sido un ámbito tradicionalmente relegado en favor de las investigaciones centradas en las grandes urbes y, en especial, sobre sus élites de poder. Idéntico desequilibrio se detecta en la cuestión de las intrusiones en el estado noble de las localidades. Esta problemática, que preocupaba principalmente al Estado por el perjuicio que generaba en su Real Erario, estuvo presente en todos los concejos y, como veremos, tuvo especial incidencia entre las medias y pequeñas poblaciones donde la autoridad regia no era tan notable como en las grandes ciudades y villas.

Hasta el siglo XVIII la política de avecindamiento y la consiguiente designación de estado al nuevo vecino se rigió de acuerdo a la ley promulgada por Enrique III según la cual únicamente los notorios hijosdalgo, de solar conocido o que tuviesen sentencia de reconocimiento como hijosdalgo estaban amparados en su franqueza e hidalguía en los concejos. El resto habían de probarla ante la Sala de Hijosdalgo ${ }^{19}$. Como ya hemos expuesto, aunque durante los siglos XVI y XVII fueron frecuentes las quejas y pleitos ante la Chancillería por intrusiones y manipulaciones de los padrones, esta ley fue aplicada con notable permisividad por parte de los concejos. Es más, realmente eran estos los que promovían las acciones judiciales ante la Sala de Hijosdalgo lo que implicaba indirectamente que el recibimiento de hidalgos estuviese condicionado a su actitud frente al supuesto hidalgo ${ }^{20}$.

${ }^{19}$ Nueva Recopilación. L. II, Tít. XI, 1. IX. Sobre el tratamiento procesal de la hidalguía durante los siglos XVI y XVII. Vid L. DíAZ DE LA GUARDIA Y LóPEZ (2008). «La hidalguía a finales del Antiguo Régimen: los "Apuntamientos" del granadino Antonio de Orejón y Haro: estudio y edición». Espacio, tiempo y forma. Serie IV, Historia moderna, 21, pp. 102-114.

${ }^{20}$ Debemos destacar dos aproximaciones a la situación de la baja nobleza en los medianos y pequeños municipios extremeños. Para finales del siglo XV y principios del XVI contamos con el trabajo de M.-C., GERBET (1989). La noblesse dans le royaume de Castille: Étude sur ses structures 
Con la llegada de la dinastía borbónica al trono español a principios del siglo XVIII se producirán cambios decisivos en muchos aspectos. En esos primeros momentos la Corona se encontraba en la urgente necesidad de aumentar los ingresos ordinarios y extraordinarios para paliar tanto la perpetua bancarrota de la Real Hacienda como para costear los gastos bélicos de la Guerra de Sucesión ${ }^{21}$. Esta situación, agravaba por los considerables retrasos que experimentaban los envíos de remesas americanas, obligó a la toma de medidas para hacer más eficiente el aprovechamiento de los recursos financieros y humanos del país.

Una de ellas fue la de controlar el número de exentos poniendo en orden los recibimientos de hidalgos en los concejos con lo que se pretendía restringir el acceso a esta nobleza exenta y así engrosar la nómina de contribuyentes a los tributos reales. Para ello se actualizó la ley de Enrique III exigiendo que todos aquellos que quisiesen ser recibidos y empadronados como hidalgos en una localidad justificasen la posesión de la hidalguía ante la Sala de Hijosdalgo. De este modo el Consejo de Castilla dictó el Real Auto acordado de 30 de enero de 1703 por el que se fijaba el procedimiento a seguir en los recibimientos de nuevos vecinos como hidalgos en los concejos:

"Los ayuntamientos de las ciudades, villas y lugares de estos reinos no hagan recibimientos de hijosdalgo de personas algunas sin que preceda la justificación que se dispone por la ley del Señor don Enrique, Nona del Título Once del libro Segundo de la Recopilación con precisa obligación de dar cuenta dentro de un mes al fiscal de la Chancillería de los que hubiesen hecho apercibimiento de proceder contra ellos y de que se les hará cargo en la residencia que se les tomare asi a los capitulares que se hallaren en dichos recibimientos como a los escribanos de su alistamiento y de la justificación que procediere a cada uno de dichos recibimientos para que vistos por dicho fiscal siendo legítima y conforme a la ley no pida cosa alguna y no lo siendo pida se despache provisión con inserción de ella y se proceda conforme a derecho y en caso de pedirse por el recibido testimonio de lo que se decidiere en estos casos a su favor se le dé con la calidad de sin

sociales en Estrémadure (1454-1516). Paris: Publications de la Sorbonne, 1979; para el siglo XVIII la investigación de Aragón Mateos destaca las dificultades de este grupo para mantener su adscripción estamental en las localidades. S. ARAgón Mateos (1990). La nobleza extremeña en el siglo XVIII. Mérida: Biblioteca Pública Municipal Juan Pablo Forner, pp. 112-122.

${ }^{21}$ Para esta cuestión en particular Vid F. Andujar Castillo (2008). Necesidad y venalidad. España e Indias, 1704-1711. Madrid: Centro de Estudios Políticos y Constitucionales. 
perjuicio del Patrimonio Real así en el juicio de propiedad como en el de posesión y para todo ello se dé el despacho necesario [...]",22.

Con esta medida se pretendía proteger los intereses del Erario Real evitando las intrusiones en el estado noble que eran tan frecuentes hasta entonces. Se restablecía así la autoridad de la Sala de Hijosdalgo como instancia suprema y única en asuntos de hidalguía, subordinando a justicias locales e hidalgos al parecer de los Alcaldes de Hijosdalgo. A partir de entonces con los juicios provisionales de dar estado conocido [de hidalgo o de pechero], también llamados Expedientes provisionales, se dictaminaría el estado que habría de corresponder al pretendiente en la localidad donde solicitaba la vecindad, previa presentación de justificaciones de filiación.

Veladamente, estos procesos implicaban la subordinación de la hidalguía y de los concejos al Estado regularizando bajo precisos criterios jurídicos una condición privilegiada que hasta entonces se venía amparando en valoraciones subjetivas como la estimación social ${ }^{23}$. Sin embargo, en contra de los deseos de la Corona, esta acreditación judicial cuyo valor legal no excedía los límites de la localidad donde se solicitaba vecindad, será aceptada socialmente como un acto positivo de nobleza de peso equivalente al de una Real Carta ejecutoria de Hidalguía ${ }^{24}$.

Con la generalización de los expedientes provisionales como vía procesal preferente decayó el número de pleitos de hidalguía, el mayor acto positivo de nobleza, desplazados por las ventajas de aquellos como su menor coste y una tramitación mucho más rápida.

Sin embargo, la orden de 1703 tuvo que afrontar una serie de obstáculos en su correcta aplicación. En primer lugar, el auto acordado pretendía romper con una serie de costumbres y vicios presentes en los recibimientos de hidalgos durante

${ }^{22}$ Novísima Recopilación. Lib. II, Tít. XI, Auto V. Con el fin de unificar criterios de edición se ha optado por modernizar la grafía de las citas textuales.

${ }^{23}$ L. DÍAZ DE LA GuARDía (1996). «Aburguesamiento de la nobleza media y baja en Castilla: los pleitos de hidalguía». En ENCISO RECIO, L. M. (Coor). La burguesía española en la Edad Moderna: Actas del Congreso Internacional celebrado en Madrid y Soria los días 16 a 18 de 1991. Valladolid: Universidad de Valladolid, p. 530.

${ }^{24}$ La Real Carta Ejecutoria sólo podía obtenerse tras un juicio plenario entre partes, es decir, en un pleito de hidalguía en sentido estricto, cuyo fallo definitivo no podía ser discutido por la justicia local; los expedientes provisionales o Reales Provisiones de dar estado conocido consistían en un juicio sumario a petición de parte con asistencia de oficio del fiscal en defensa de los derechos del Patrimonio Real, librándose un despacho en el que se amparaban sus privilegios únicamente dentro del concejo con el que litigaba. Vid M. S. Martín Postigo (1990). La Sala de Hijosdalgo de la Real Chancillería de Valladolid. Valladolid: Ámbito, pp. 27-30. 
siglos por lo que su correcta aplicación no fue tan sencilla. Estas malas prácticas, arraigadas durante siglos entre empadronadores, escribanos y justicias locales, daban lugar a irregularidades que, ocasionalmente, cobraban grandes proporciones especialmente en territorios aislados. Este era el caso del Reino de Galicia en donde la "peculiar" forma de hacer padrones de distinción dio lugar a las quejas del fiscal de Chancillería:

"Digo que en la desorden que ha habido y hay en la mayor parte de vuestro Reino de Galicia en no hacer los padrones de servicio ordinario y moneda forera y demás repartimientos correspondientes al estado llano, en auténtica forma, por culpa y omisión de las justicias ordinarias que faltando en esto a su obligación han permitido y permiten se hagan dichos padrones y repartimientos por los repartidores y vecinos de las ciudades, villas y lugares simples sin autoridad alguna haciéndoles entre sí cada año y fenecida la cobranza, lo rompen sin dejar copia ni razón alguna de ellos en las archivos de los ayuntamientos o concejos de dichos pueblos se han reconocido muchos inconvenientes originando y originan muchos pleitos a ambos estados experimentándose que muchos que son pecheros llanos se introducen en el del estado llano [sic]; también la malicia de empadronar y pechar a los que son conocidos y notorios hijosdalgo siéndoles fácilmente probar su nobleza, faltando dichos padrones e instrumentos principales para ello y por lo que lo referido es en perjuicio común y de vuestro Real Patrimonio $[\ldots]^{, 25}$.

A partir de 1703 el fiscal de la Chancillería de Valladolid, como defensor del Patrimonio Real ante la Sala de Hijosdalgo, hará constar su descontento ante el incumplimiento del auto acordado, bastante frecuente durante los primeros años en que a la falta de observancia del mismo se sumaba la fuerza de la costumbre:

“[...] aunque desde el dicho mes de febrero del año de setecientos y tres en que se dio principio a la observancia de dicho auto de vuestro Concejo se han despachado muchas provisiones de las referidas previniéndose, especialmente en las de dar estado conocido, se use de ellas dentro de treinta dias y en otros treinta se presenten con sus diligencias ante $V$. A. donde no queden sin efecto alguno, muchas ellas no se han presentado solo con haber logrado los pretendientes haber sido recibidos por hijosdalgo y quedarse en la posesión de tales sólo con dicho recibimiento por tolerancia de los concejos no lo pudiendo ni debiendo hacer sin que precedan las solemnidades que previene dicho auto de vuestro Consejo y aprobación de $V$.

${ }^{25} A R C h V$, Sala Hijosdalgo-Pleitos, C. 1152-51. Petición del fiscal de la Real Chancillería de Valladolid para que se hagan padrones de distinción de estados en el Reino de Galicia (1701). 
A y porque lo referido es en fraude y perjuicio de vuestro Real Patrimonio digno de remedio que para ocurrir al que convenga $[\ldots]^{, 26}$.

Podría decirse que el problema real no residía tanto en aquellos que se aprovechaban de esas provisiones despachadas por la Sala para ser recibidos como hidalgos como en los propios concejos que, por ignorancia u omisión, los permitían. Esto era un síntoma inequívoco de la laxitud con que los municipios acataban las leyes reales sobre todo en los pequeños núcleos rurales organizados en concejo abierto que mantenían buena parte de su tradicional autonomía.

A pesar de las penas que conllevaba el incumplimiento del auto acordado no fueron extraños los municipios que ventilaban este tipo de asuntos internamente y sin el beneplácito de la Sala ${ }^{27}$; en otras ocasiones, aunque se acatase, la falta de rigor a la hora de ejecutar las diligencias por parte de autoridades y escribanos locales producía grandes irregularidades en las informaciones de filiación remitidas a la Chancillería que sólo podía poner orden cuando se elevaba una queja al fiscal o se detectaban falsedades evidentes en los procesos.

A pesar de todo no cabe duda que el citado auto constituyó un hito legal a la hora de regular definitivamente los accesos a la hidalguía su aplicación no estuvo exenta de polémica como en la villa de Briones donde, interpretando la ley con efectos retroactivos, decidió en 1708 se comunicó un oficio por el estado llano a Domingo de Echavarría, recibido como hidalgo antes de que entrase en vigor dicha orden, que no tuvo más remedio que iniciar un expediente provisional ante la Sala de Hijosdalgo ${ }^{28}$.

Como puede observarse, este tipo de irregularidades venían derivadas de la falta de formalidad legal en los recibimientos en los que la actitud arbitraria y los intereses particulares de las justicias locales y los propios empadronadores encargados de la elaboración de los padrones de distinción de estados se convertían en factores más relevantes que la propia legislación real.

Unos años después, lejos de normalizarse la situación, la eliminación del servicio de moneda forera y milicias en $1724 \mathrm{y}$ de los padrones distintivos que se

${ }^{26}$ ARChV, Sala Hijosdalgo-Pleitos, C. 1962-9. Queja del Fiscal de Chancillería sobre que los concejos reciben hidalgos sin atender a las solemnidades del auto de 1703. (1704)

27 J. FAYARD (1983). op. cit., p. 189. La autora destaca que hacia 1752 el incumplimiento del auto acordado de 1703 en Asturias continuaba siendo sistemático por parte de la justicia ordinaria que ejecutaba los recibimientos sin el correspondiente permiso de la Chancillería de Valladolid.

28 ARChV, Sala Hijosdalgo-Pleitos, C. 1684-4. Real Provisión de dar estado conocido de Domingo de Echavarría (1709). 
realizaban para tal fin dio lugar a un mayor desorden de estados. Las intrusiones propiciadas por la falta de tales alistamientos hicieron que en 1736 la Chancillería de Valladolid ordenase la elaboración de un padrón general en toda su jurisdicción y que en adelante se ejecutase ordinariamente cada siete años. Con esta medida se refrendaba el valor legal que la Corona otorgaba a los padrones como evidencia positiva para determinar la calidad del linaje.

El problema era que en la elaboración de padrones se producían toda serie de errores, omisiones y fraudes, incrementados a medida que la Corona le otorgaba a estos documentos una mayor importancia probatoria. La misma ejecución de un padrón podía dar lugar a negocios ilícitos y a graves conflictos dentro del vecindario. En 1757, en la villa cántabra de Cartes, el alcalde ordinario por el estado noble, aprovechando su posición de poder, realizó un padrón sin las solemnidades precisas ni en el año correspondiente, chantajeando y amenazando a los vecinos y solicitándoles cantidades de dinero para incluirlos como hidalgos ${ }^{29}$. Resulta interesante observar cómo, contra lo que pudiese pensarse, no siempre eran pecheros los únicos implicados en tales delitos sino también los propios nobles quienes, en función de sus propios intereses, contribuían a alterar el orden social.

La pretensión del Estado de imponer una hidalguía política y civil demostrable a través de actos jurídicos o actos positivos de nobleza no fue obstáculo alguno para que persistiesen los actos de intrusión, muchos de ellos tolerados por los propios concejos, eludiendo así la autoridad de la Sala de Hijosdalgo.

Durante los años sesenta y setenta puede apreciarse un considerable incremento de los procesos judiciales por intrusiones colectivas, sobre todo en los pequeños núcleos rurales ${ }^{30}$, coincidiendo precisamente con la decisión de la Corona de apuntalar su control sobre la población por medio de la extensión del sistema de padrones de distinción de estados a zonas hasta entonces exentas de ellos ${ }^{31}$ y la confección de censos cada vez más precisos que le permitían conocer con mayor fiabilidad los recursos financieros y humanos del país. Los resultados de esta

${ }^{29}$ ARChV, Sala Hijosdalgo-Pleitos, C. 1572-2. Información sobre los abusos cometidos por el juez ordinario de Cartes contra algunos vecinos en la elaboración de padrón (1757).

${ }^{30}$ Por mencionar algunos procesos por intrusión en el estado de hijosdalgo: $A R C h V$, Sala Hijosdalgo-Pleitos, C. 1925-4 Valle de Valderredible (1768). ARChV, Sala Hijosdalgo-Pleitos, C. 1800-11 Valle de Piélagos (1771). ARChV, Sala Hijosdalgo-Pleitos, C. 1616-3 Valle de Cieza (1773). Todos en la actual comunidad autónoma de Cantabria.

${ }^{31}$ Es el caso de la comarca de Cameros en La Rioja en donde a partir de 1767 se impondrá la elaboración regular de los padrones de distinción de estados. Vid J. A. GARCíA-CuERDAS SÁnCHEZLollano (2009). Villoslada de Cameros: pueblo de hidalgos, trashumantes y emigrantes. Logroño: Instituto de Estudios Riojanos, pp. 220-222. 
política fueron evidentes: entre el censo de Aranda de 1768 y el de Floridablanca de 1787 se redujo la población noble en 300.000 individuos.

El segundo gran problema fue la falta de medios y personal para imponer con rigor el auto acordado de 1703. En tales condiciones, la Sala de Hijosdalgo se enfrentaba a la ingente misión de hacer cumplir las leyes dentro de una extensa jurisdicción. Esto, unido a la falta de control sobre las diligencias sobre hidalguías, favorecía la proliferación de falsificaciones y, en consecuencia, las intrusiones.

En este sentido, un incidente llamativo fue el de la villa orensana de Viana del Bollo. Aquí las intrusiones colectivas vinieron derivadas del incumplimiento sistemático de las disposiciones sobre empadronamiento de hidalgos. La Real Chancillería, conocedora de esta infracción, decidió enviar en 1760 un comisionado para que se hiciese el primer padrón de distinción de estados del vecindario después de 60 años. Lógicamente, tras un incumplimiento tan prolongado la forma de descubrir a los hidalgos intrusos fue la de aplicar el auto acordado de 1703, alistando como pecheros a todos los vecinos que no presentasen la correspondiente justificación de hidalguía ${ }^{32}$. La oposición a esta medida dio lugar a numerosas protestas e incidentes. Las consecuencias trascendieron a la Real Chancillería con el seguimiento de una pesquisa criminal sobre los actos de violencia así como numerosos pleitos de hidalguía en años posteriores.

Otro caso aún más clamoroso de fraude colectivo fue el de la ciudad de Santander, un centro comercial en auge en la que se asentaban ricos mercaderes y negociantes, muchos de los cuales no poseían una condición de nobles que, en cambio, sí tenían muchos de los naturales, de poder económico mucho menor. En 1772, tras la misteriosa desaparición de todos los padrones que iban a servir de referencia para elaborar el de ese mismo año, la ciudad solicitó que se volviese a conceder la hidalguía que gozaba antaño todo el vecindario. Esta medida favorecía indudablemente a todos los plebeyos, especialmente los poderosos a los que ofendía que se notase su inferior condición. Contradiciendo esta petición se ordenó que, al igual que en Viana del Bollo, se inscribiesen como hidalgos sólo a aquellos que justificasen su calidad mediante ejecutorias o expedientes provisionales de la Real Chancillería ${ }^{33}$. Aunque esta decisión promovió una avalancha de solicitudes

32 ARChV, Sala Hijosdalgo-Pleitos, C. 1742-10. Memorial ajustado sobre los incidentes acontecidos en Viana del Bollo tras la visita del comisionado de la Real Chancillería de Valladolid (1760).

33 A. Medina GonzÁlez (1989). «Como perdió la hidalguía la ciudad de Santander». Altamira. Revista de Estudios Montañeses, 48, pp. 177-179. 
de expedientes provisionales en la Chancillería la nómina de nobles de la ciudad quedó considerablemente reducida.

Debemos apuntar que, a diferencia de lo que ocurrirá en poblaciones menores, parece ser que la Chancillería no investigó la sospechosa desaparición de los padrones de Santander. Quizá pesó más el deseo de no enfrentarse con la potente elite local implicada en los sucesos. De hecho, años más tarde la persistencia del sector plebeyo de la élite burguesa santanderina, considerando vejatorias estas distinciones, consiguió que la Corona cediera a sus peticiones y suspendiese la ejecución de padrones ${ }^{34}$.

En este caso los promotores del fraude son evidentes: plebeyos enriquecidos que pretendían introducirse en el estado noble en connivencia con las autoridades locales, utilizando la desaparición de los padrones como única alternativa desesperada ante el endurecimiento de los recibimientos que hacía más difícil el acceso a la hidalguía que por los métodos tradicionales.

Como sí la tarea de erradicar las malas prácticas en los concejos no fuese suficiente también la propia Chancillería se vio expuesta a malos usos y prácticas fraudulentas. En 1723 los Alcaldes de Hijosdalgo denunciaron las prácticas llevadas a cabo por los escribanos de cámara que revestían y adornaban las Reales Provisiones de dar estado conocido simulando la apariencia de auténticas ejecutorias de hidalguía y sobrepasando su valor legal:

"[...] habiendo llegado a su noticia haber expedido de algún tiempo a esta parte por los oficios de los escribanos de cámara de la sala competente de los autos que se suelen dar en ella a los recibidos al estado de hijosdalgo [...] conforme a lo dispuesto por el auto acordado del Consejo, estando el concejo que hizo recibimiento de un mismo acuerdo [...] se han obtenido en semanería diferentes despachos escritos en pergamino o vitela registrada o sellados con sello de plomo pendiente de seda hablando su ejecución con todas las justicias del Reino a manera de Cartas Ejecutorias incorporados instrumentos con mandato respectivamente semejantes a estas lo que siendo contrario a las ordenanzas y práctica de esta Chancillería es de no menores perjudiciales consecuencias al Real Patrimonio dando motivo sobre el crecido dispendio de las partes que clandestinamente las solicitan a aquellos concejos ignorantes requeridos con ellas se les persuada son cartas ejecutorias confirmándoselo con el principio y contexto para que de ningún pueda dejar de ser recibido en cualquier lugar y mantenidos siempre en la calidad de hijosdalgo los que consiguen semejantes despachos asegurándose

${ }^{34}$ Ibidem, p. 184. 
por este fraudulento medio en que no se les pase a poner demanda en lo principal ni ser inquietados en la posesión y por lo que importa extirpar este grave desorden mandaron que de hoy en adelante ninguno de los escribanos de cámara de la Sala [...] refrenden ni despachen testimonios, provisiones $n i$ otros despachos de los autos expresados ni otros semejantes escritos en pergamino o vitela $[\ldots]^{35}$."

De nuevo, son los propios hidalgos, en este caso reconocidos por la propia justicia real, los que participan en la manipulación, aunque esta vez no sea de orden genealógico sino de los efectos jurídicos de un real despacho.

Aunque oficialmente se prohibiese este tipo de prácticas la realidad es que nunca fueron totalmente erradicadas ante la gran apetencia de los propios hidalgos por lucir los mayores signos de distinción. Esto no solo se tradujo en una gran demanda de esas acreditaciones de nobleza sino también en el deseo de engalanarlas con el mayor oropel posible ya fuese para aparentar una ejecutoria o con el ingenuo ánimo de dotarla de una mayor pompa y boato. Sin rubor alguno, los despachos expedidos por la Chancillería continuaron siendo adornados con el escudo de armas del apellido del solicitante y encuadernados en pergamino e hilos de colores a imitación de las auténticas ejecutorias.

No resulta difícil imaginar toda clase de negocios más o menos lícitos que pudieron rodear estas operaciones. En el caso de las certificaciones de genealogías y entronques, función exclusiva de los Reyes de Armas, el intrusismo profesional alcanzó tal punto que la Corona tuvo que prohibir expresamente su ejercicio a aquellos que no tuviesen el título ${ }^{36}$.

Por último, y sin excluir en ningún caso el fraude, también hemos de considerar el peso que ejercía el inconsciente colectivo de la época dentro de esta confusión entre lo que era una Real Provisión de estado conocido y una Real Carta Ejecutoria fruto de un pleito. Esta era una distinción de naturaleza procesal evidente para un letrado versado en la materia pero indiferente a ojos de la mayor parte de la población, ignorante y desconocedora muchas veces de las leyes y, más aún, de sus procedimientos. De hecho el vocablo "ejecutoria" adquiere una acepción genérica asociada a todo documento probatorio. En cuanto al desconocimiento de los efectos legales de una y otra también podemos hallar su causa en un razonamiento propio de la mentalidad estamental ya que si alguien estaba reconocido como hidalgo en

35 ARChV, Sala Hijosdalgo-Pleitos, C. 1994-8. Orden de los alcaldes de hijodalgo para que los escribanos de cámara no refrenden provisiones en pergamino (1723).

${ }^{36}$ Novísima Recopilación. L. XI, Tit. XXVII, 1. I 
un determinado lugar se presuponía que dicha calidad era igualmente transmisible a los demás pues se entendía como una calidad personal, no territorial.

Como analizaremos en las páginas siguientes, las irregularidades más graves de todas, y seguramente también las más frecuentes, se daban en la elaboración de las diligencias justificativas sobre la hidalguía. Elaboradas por escribanos locales, padecían los efectos de las prácticas ilícitas que resultaban de la connivencia de estos agentes con el solicitante y que generaban un negocio lucrativo. De este modo se falseaban partidas sacramentales y padrones convirtiendo una notoria ascendencia plebeya en una noble.

\section{INTRUSOS EN LA COMARCA DE LACIANA: UN CASO PARADIGMÁ- TICO}

Con el análisis de este proceso pretendemos arrojar luz sobre los responsables de las intrusiones colectivas en los concejos rurales así como de las estrategias empleadas para lograr este objetivo. Para ello, los sucesos que acontecieron en Laciana constituyen un buen caso práctico para ilustrar este tipo de conflictividad dada la acumulación de infracciones, de las artimañas empleadas para transgredir la ley así como los resortes de actuación de la justicia regia ante las mismas.

Esta comarca leonesa presentaba a mediados del siglo XVIII un alto porcentaje de hidalgos. Según el padrón de 1761, frente a un $60 \%$ de pecheros había un $40 \%$ de hidalgos ${ }^{37}$. Esto se asemeja más a la realidad del territorio asturiano colindante que a la de la meseta donde la proporción era claramente inferior.

El relato de los hechos es el siguiente ${ }^{38}$. El asalto del archivo municipal ocurrido en abril de 1760, con robo y destrucción de padrones incluido, llegó a oídos del Fiscal de la Chancillería de Valladolid quien solicitará a la Sala de Hijosdalgo el envío de un receptor para hacer las averiguaciones precisas sobre este suceso. Estas pesquisas vinieron a destapar un fraude mucho mayor ya que el asalto del archivo tenía como objetivo encubrir las intrusiones de varios vecinos en el estado noble y la falsificación de justificaciones de nobleza.

Según avanzan las investigaciones se empiezan a evidenciar nuevas irregularidades: el archivo, en lugar de en una iglesia o en el ayuntamiento, se custodiaba en la casa de un escribano local, Pedro Simón de la Lama, supuestamente elegida por su proximidad al mismo. Pronto recaerían sobre este las

\footnotetext{
37 J. L. Gómez BArthe y Álvarez (2004). «Los hidalgos de Laciana». Hidalguía, 306, p. 658.

${ }^{38}$ Los datos expuestos proceden del memorial ajustado del pleito. ARChV, Sala HijosdalgoPleitos, C. 1875-1, sin foliar.
} 
sospechas de su complicidad en el robo al comprobarse la facilidad con que los ladrones habían accedido a la casa de donde únicamente se sustrajeron los padrones de distinción de estados, sin duda, con la aviesa intención de ocultar los orígenes de los vecinos.

Pero los interrogatorios a los vecinos del concejo no sólo empezaron a despejar las dudas sobre la autoría del hurto sino que también desvelaron que detrás de este incidente se ocultaba un fraude colectivo de mayor magnitud. En principio, sin precisar nombres, pecheros e hidalgos se imputaron mutuamente la autoria del robo. Unos para con la intención de ocultar sus oscuros orígenes; los otros para perjudicar a los nobles. Poco a poco empieza a salir a la luz la presencia de intrusos en el estado hidalgo. Ante los escasos resultados obtenidos en la cuestión del robo los interrogatorios se reorientaron hacia la delación de los intrusos en el estado noble. Aquí se deja sentir el malestar existente por la intrusión de algunas familias en el estado noble desde hacía diez años y que parecía estar en la génesis del problema:

"[...] en aquel concejo hay tres clases de personas y estados: hidalgos antiguos, cuyos padres, abuelos y más ascendientes gozaron de este estado; pecheros, que actualmente contribuyen como los que lo son; y la tercera se compone de hidalgos nuevos que se han hecho tales de diez años a esta parte, los cuales y sus causantes estuvieron empadronados por pecheros y lo fueron llanos y por tales vieron repartirles y pagar sin resistencia y obtener los oficios por el estado general y que los que se han intrusado son, según exponen separada y respectivamente los Ribas, los Álvarez que se han añadido el apellido de la Puerta para entroncar con los de este apellido, que residen en Palacios y Cuevas de Sil; los Alonsos, que antes se llamaban Alfonsos; los González; los Piñeros; los Lamas; y los Cosmenes"

El descaro de los intrusos resulta sorprendente pues siendo su pechería notoria en el vecindario y, a pesar del conocimiento que tenía del fraude, habían gozado de los privilegios de hidalgos durante más de diez años. Por ello lo más preocupante de esta declaración es la aparente tolerancia de los vecinos pecheros ante una situación de flagrante ilegalidad que subvertía el orden estamental local.

En cuanto a la descripción de los tres estados parece evidente que hay una expresa identificación entre hidalguía y exención fiscal derivando en ciertos tintes despectivos en la expresión "hidalgos nuevos" ya que la facilidad con la que algunos pecheros habían conseguido convertirse en hidalgos en su mismo concejo había depauperado su consideración como nobleza de sangre.

Descubierta la raíz del problema, los testigos comenzaron a delatar a los responsables de las falsificaciones en las justificaciones de filiación que, en 
algunos casos, habían aprovechado para convertirse ellos mismos en hidalgos. De esta forma se inculpa a Pedro Simón y Juan Presentado de la Lama, a Antonio González Lorenzana, los tres escribanos del concejo -este último ya condenado anteriormente por falsedades-y, finalmente, a Francisco Álvarez, alias Farrucón, amanuense de Lorenzana.

Resulta especialmente interesante la figura de Francisco Álvarez, que terminará siendo encausado como el principal responsable de las falsificaciones de instrumentos de filiación y posesión. Este realizaba sus turbios negocios errando entre el concejo asturiano de Somiedo -de donde era natural, como denota su apodo- y Laciana. Sus prácticas fraudulentas, la falta de residencia fija y de un oficio reglado así como su propio comportamiento lo identifican como un individuo ambulante de mala reputación, un delincuente de pluma que a cambio de unas monedas hacía hidalgos. De hecho, según los diferentes testigos, su jactancia llegaba a tal punto que su labor era un secreto a voces que él mismo se había encargado de propalar en varias ocasiones:

“[...] estando el referido Álvarez, con el escribano Lorenzana en una taberna, dijeron ambos a los que alli se hallaban: amigos buen ánimo, que aqui está Valladolid para hacer hidalgos; que yendo de aquí bien dispuesto, allá todo pasa. ${ }^{39}$

De ser ciertas las palabras puestas en la boca de Farrucón, este no hace más que constatar una evidencia: lo sencillo que era obtener el reconocimiento de la posesión de hidalguía en la Real Chancillería gracias a la falsificación de las justificaciones de filiación y, lo que es peor, la falta de respeto que parecía inspirar la Sala de Hijosdalgo, ignorante de las falsedades en muchas informaciones que le llegaban.

Poco antes del asalto al archivo, el estado general había decidido en junta dar cuenta al Fiscal de la Chancillería de los intrusos, circunstancia que desencadenó el robo de documentos. Aunque poco inusual, lo cierto es que esta secuencia completa de hechos (falsificación-intrusión colectiva-destrucción de archivos) ilustran a la perfección los elementos que integran el proceso de formación y encumbramiento del fraude colectivo.

39 Ibídem. Otro de los testigos declara que "[...] caminando dicho Farrucón con Juan Presentado de la Lama y con los del apellido Ribas, a ejecutar las filiaciones de estos hacia la provincia del Bierzo; habiéndoles encontrado y preguntándoles a dicho Farrucón que adónde iba, le respondió iba a ver si podía hacer hidalgos a aquellos caballeros, los Ribas." 
Contamos con otro suceso similar acaecido en Miranda de Ebro unos años antes. De nuevo, entre los implicados encontramos a un escribano sin número además de un maestro de primeras letras, ambos personajes de mala fama en la villa, a los que se acusaba de la falsificación sistemática de los instrumentos utilizados para justificar las hidalguías. Otra vez el desencadenante de la pesquisa criminal fue el asalto al archivo municipal con el que se pretendía encubrir estas prácticas fraudulentas ${ }^{40}$.

En ambos casos, las irrupciones violentas en los archivos y los robos de padrones constituyen sucesos extraordinarios que han de ser interpretados como actos desesperados ante la inevitable intervención judicial con el fin de encubrir otro tipo de fraudes mucho más importantes y frecuentes: la falsedad en las informaciones de nobleza. Tampoco parece una casualidad que en ambos casos los responsables fuesen escribanos y, más concretamente, amanuenses errantes y sin oficio regulado que vendían sus servicios al mejor postor como auténticos mercenarios de la pluma.

Volviendo a Laciana parece que hacia 1762 la situación había retornado a la normalidad. Ese mismo año, con el fin de quedar exentos del servicio de quintas de soldados, los nobles de Laciana solicitaron a la Chancillería de Valladolid el padrón realizado en el concejo el año anterior, petición que no despertó ninguna queja entre el estado llano ${ }^{41}$.

A largo plazo, este tipo irregularidades sí que tendrían consecuencias a nivel judicial pues la certeza de que los procesos por falsificación y fraude documental como los de Laciana se multiplicaban ${ }^{42}$ obligó a la Sala de Hijosdalgo a adoptar

${ }^{40}$ ARChV, Sala Hijosdalgo-pleitos, C. 1937-1. Resulta interesante como los testigos inciden en la conducta moral reprobable de los inculpados: pendencieros, adúlteros, bravucones, etc. añadiendo a sus negocios ilícitos un perfil sociológico que les define como delincuentes en todos los sentidos.

41 J. L. GÓmez Barthe y Álvarez (2004). art. cit., pp. 657-658.

42 Durante los años sesenta y setenta se van a iniciar varios procesos por fraude documental contra escribanos. Sin duda, los casos en que se destapaba el fraude eran una pequeña parte dentro de la totalidad del fraude real. $A R C h V$, Sala Hijosdalgo-Pleitos, C. 1574-10. Pleito del fiscal contra Bernardo Villegas, vecino y escribano de Pie de Concha (Cantabria) por falsificaciones en los padrones y libros de iglesia realizados por él mismo (1763). ARChV, Sala Hijosdalgo-Pleitos, C. 1615-2. Pleito del fiscal con Juan de las Cuevas, Juan Manuel de Terán, escribano del número y otros, todos vecinos de Santa Cruz (Cantabria), sobre suplantación y falsedad de los instrumentos de filiación y posesión de hidalguía del dicho Juan de las Cuevas (1764). ARChV, Sala HijosdalgoPleitos, C. 1474-1. Pleito contra Lorenzo Sáenz de Cenzano, vecino y escribano de Alcalá de Henares por falsificación documental (1771). 
medidas correctoras ante la multiplicación de estas prácticas fraudulentas entre los escribanos locales:

"[...] habiendo experimentado en los expedientes de hidalguía no solo algunos defectos en la formalidad con que deben de practicarse las justificaciones que se previenen por auto acordado de treinta de enero de mil setecientos y tres muy en varios fraudes y monopolios con cuyos reprobados medios intentan muchos ingerirse a el estado de hijosdalgo que no les corresponde o por no tener derecho alguno o por haber perdido legalmente el que pudieron tener y proviniendo este desorden principalmente de los escribanos de los pueblos a quienes procuran ganar los pretendientes para que den testimonio de hallarse en los padrones, las partidas que se necesitan para fundar su derecho sin explicar como debieran el estado de ellas cuando muchas veces son puestas por ellos mismos logrando igualmente que certifiquen de la indistinción de los lugares y libertad de pechos sin expresar con claridad la reputación que haya tenido la familia y demás autos que pueda haber en ellos para distinguirse las personas de uno y otro estado todo con el fin de sorprender la vigilancia de la Sala [...] ${ }^{, 43}$.

Por tanto, resulta evidente la preocupación de la Sala por la falsificación de las justificaciones de filiación, inquietud acentuada por incidentes como los descritos en Laciana y Miranda de Ebro. Pero, además, lo que más preocupaba al tribunal eran los efectos perniciosos que tales prácticas tenían el orden establecido y el daño sobre los intereses de la Hacienda regia. Con el fin de corregir estas deficiencias e irregularidades el auto dictaba una serie de modificaciones en los procedimientos de compulsa de las justificaciones haciendo obligatoria la asistencia de la justicia local así como de un informante en representación del concejo.

\section{CONCLUSIONES}

La hidalguía, como base de la nobleza en España, fue objeto de deseo durante todo el Antiguo Régimen por lo que las prácticas poco transparentes o netamente fraudulentas siempre tuvieron buena acogida entre los aspirantes a la nobleza. Dentro del ámbito local, era ambicionada tanto por la exención fiscal que concedía en primera instancia como por la superior consideración del linaje a medio y largo plazo.

A partir de la implementación del auto acordado de 1703 hubo un antes y un después en materia de hidalguía. La imposición de un criterio judicial para probar

43 Auto dictado por la Sala en 19 de diciembre de 1778 que, a partir de la fecha, aparecerá insertado dentro de las Reales Provisiones de dar estado conocido. 
la posesión de la hidalguía permitió a la Corona un mejor control de los accesos a la nobleza, transformando una nobleza basada únicamente en la notoriedad y la común opinión en otra apoyada en la evidencia judicial: una nobleza de papeles. El Estado, deseoso de eliminar la informalidad que la acompañaba, la transformó definitivamente en categoría jurídica que debe ser probada y sometida su reconocimiento bajo ese criterio legal. Por tanto, debemos interpretar esta medida como un giro centralizador tanto en la organización y composición de la jerarquía nobiliaria como en lo relativo a las competencias de los concejos, sometiendo ambas instituciones a los dictados de la monarquía absoluta de Felipe V.

A pesar de todas estas reformas, el fraude genealógico -realidad inherente al propio sistema estamental- consiguió adaptarse mediante la manipulación de los padrones y las justificaciones de filiación propiciada por una falta de rigor y de vigilancia en su ejecución. Todo ello tuvo considerables repercusiones negativas en el prestigio del estado hidalgo al sublimarse el valor del documento no siempre debidamente contrastado como prueba de nobleza. Y es que, como hemos podido comprobar la prueba documental, encumbrada durante el siglo XVIII como evidencia de mayor valor y credibilidad que la testifical, no se libró del fraude y la manipulación interesada. La cuestionable fiabilidad de este tipo de documentación debe servir al historiador para recordar la importancia del análisis crítico de la información, incluso de aquella de naturaleza jurídica, pues no olvidemos que la objetividad es un principio teórico que en muchas ocasiones la mano del hombre acomoda de acuerdo a sus intereses. 
